\title{
A Review on General Nutritional Compounds and Pharmacological Properties of the Lentinula edodes Mushroom
}

\author{
Tiane Cristine Finimundy' ${ }^{1}$ Aldo José Pinheiro Dillon² ${ }^{2}$ João Antônio Pêgas Henriques', \\ Mariana Roesch Ely 1 \\ ${ }^{1}$ Laboratory of Genomics, Proteomics and DNA Repair, Institute of Biotechnology, University of Caxias do Sul, \\ Caxias do Sul, Brazil \\ ${ }^{2}$ Laboratory of Enzyme and Biomass, Institute of Biotechnology, University of Caxias do Sul, Caxias do Sul, Brazil \\ Email: mrely@ucs.br
}

Received 1 March 2014; revised 20 April 2014; accepted 30 April 2014

Copyright (C) 2014 by authors and Scientific Research Publishing Inc.

This work is licensed under the Creative Commons Attribution International License (CC BY). http://creativecommons.org/licenses/by/4.0/

c) (i) Open Access

\begin{abstract}
Lentinula edodes is a macrofungus with great potential for therapeutic applications and serves as a model for investigating functional fungi properties and isolating pure compounds for pharmaceutical use. Mushrooms have a great nutritional value and present medicinal molecules including polysaccharides, terpenoids, sterols and lipids, that participate actively in several human disorders and modulate mechanisms involved in the immune system regulation. This review will focus on general nutritional compounds and pharmacological properties of L. edodes.
\end{abstract}

\section{Keywords}

Lentinula edodes, $\beta$-Glucans, Therapeutic Applications, Review

\section{Introduction}

Over the past 25 years, new natural drugs have been approved for the treatment of human diseases. Natural products play a very important role in the process of discovery and development of drugs, including the treatment of chronic diseases such as cancer [1]. For hundreds of years, medicinal mushrooms are used as decoctions and essences, and are applied as alternative medicine in Korea, China, Japan and eastern Russia [2]. A wide variety of compounds that occur naturally have proven active to protect against the development of tumors [3] and inflammatory processes [4]. The most investigated compounds are polysaccharides which are present in the whole structural composition mushrooms, among many effects are the antitumor and activation of the host 
immune response [5]. A number of polysaccharides have been isolated from basidiomycete [6] and are represented as homo- and heteropolymers, especially $\beta$-configuration glucans. One of the active compounds responsible for the immune effects is in the form of complex polysaccharides known as $\beta$-glucans, which are ubiquitously found in bacterial cell walls or yeast [7] [8]. The genus Lentinula sp. grows in gregarious on fallen wood of a wide variety of deciduous trees, in a warm, moist climate. Most of these are raised for artificial cultivation of shiitake mushroom and occurs naturally throughout Southeast Asia [9]. Lentinula edodes species is the most famous (Figure 1), and has been used as a model to investigate the functional properties and isolate pure compounds for pharmaceutical use.

L. edodes has shown to present medicinal compounds, including polysaccharides, terpenoids, sterols and lipids, which are effective in treating various tumors and infections, among other activities which are still being studied [10].

In vitro and in vivo investigations have demonstrated the medicinal effect of glucans as modulators of humoral and cellular mediators of interleukin (IL), activators of macrophages, T-helper and natural killer (NK), protecting the body against bacteria, viruses, fungi and parasites. Modulation of the anti-inflammatory response has also investigated [5]. In Japan, $\beta$-glucan is used as natural immunostimulant for cancer treatment since 1980. $\beta$-Glucans are also effective against allogeneic, syngeneic, and even autochthonous tumors [11].

The literature has reported the presence of various compounds such as fractionated extract from mycelium $L$. edodes (LEM) and the aqueous precipitate extract extracted from the mycelium (LAP). Both LEM and LAP contains various sugars such as galactose, arabinose, xylose, mannose and fructose, among others [12]. These extracts have revealed a strong anti-tumor activity in vivo. From the fractionation of LEM, lignin (80\%), carbohydrates (10\%) and protein (10\%) are obtained, together with a complex known as EP3 immuneactive [9] [13].

From the harvest of the mycelium, we also obtained amino acids (serine, threonine, alanine and proline), the KS-2 peptide, $\alpha$-mannan, which are capable of inducing the production of interferon and effectively inhibit the development of cancer [14] [15].

Numerous clinical trials are currently under study in the USA and several European countries. Others Basidiomycetes species also present biologically active compounds of $\beta$-glucans like Pleuran for Pleurotus sp and Lentinan for L. edodes [16]. Some of these important effects will be discussed in this review.

\section{General Nutrition Componentes of $L_{\text {. }}$ edodes}

Mushrooms have a great nutritional value since they are quite rich in protein, with an important content of essential amino acids and fiber. The dietary fiber present in L. edodes (Shiitake) consist of soluble and insoluble structures. In the water-soluble are found the $\beta$-glucans and proteins. In the non-soluble fraction, salts are extracted only with acids or alkalis, and found the polyuronide (acidic polysaccharide), hemicellulose, $\beta$-glucan chains with heterosaccharide, lignin, and chitin. They also provide a nutritionally significant content of vitamins (B1, B2, B12, C, D, and E) [17]. Are shown in Table 1 the main compounds. The aroma components include alcohols, ketones, sulfides, alkanes, fatty acids, among others [13] [18]. The main constituents which are volatile like matsutakeol (1-octen-3-ol) ethyl, n-amyl ketone and the characteristic aroma of shiitake was identified as 1,2,3,5,6-Pentathiepane [19]. Edible mushrooms are a high nutritional quality of food and have been used as an

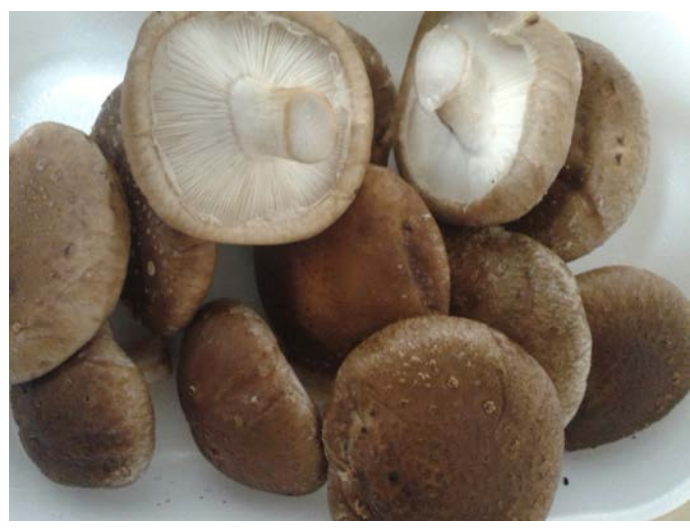

Figure 1. Morphology of the Lentinula edodes. 
Table 1. Main compounds found in edible mushrooms.

\begin{tabular}{|c|c|c|c|c|c|}
\hline \multirow{2}{*}{ Fatty acid } & \multirow{2}{*}{ Free sugars } & \multicolumn{2}{|c|}{ Polysaccharides } & \multicolumn{2}{|c|}{ Trace elements } \\
\hline & & Soluble & Insoluble & Vitamins & Minerals \\
\hline Linoleic & Trehalose & Heteroglycans & heteroglycan & Pro-vitamin D-2 & $\mathrm{Fe}$ \\
\hline Palmitic & Glycerol & Heterogalactans & polyuronide & Pantothenic acid & $\mathrm{Mn}$ \\
\hline Tetradecenoic & Mannitol & Heteromannans & $\beta$-glucan & B1 & $\mathrm{Ca}$ \\
\hline Oleic & Arabinol & Xyloglucans & Chitin & B2 & K \\
\hline Stearic & Mannose & & & B6 & $\mathrm{Zn}$ \\
\hline Myristic & Arabinose & & & B12 & $\mathrm{Cd}$ \\
\hline
\end{tabular}

alternative to dietary protein supply in countries with high malnutrition rate. The chemical and nutritional characteristics of mushrooms vary in function after harvest, and processing.

\section{Immunomodulation and Anti-Tumour Effects of $L$. edodes}

Edible mushrooms have been reported to generate beneficial effects on health and in the treatment of disease through its immunomodulatory and antineoplastic properties [20]-[22].

Investigations related to the presence of anti-tumor substances present in mushrooms started in Japan in the late 1960's. Evaluations conducted with macrofungi confirmed the effectiveness of the extracts of the fruiting bodies and mycelia in the inhibition of various cancer cell lines [2] [23]-[25]. The immunomodulatory effects of the mushrooms are well described in the literature and are related to the increased function of monocytes in the production of Interleukin-1 [11] [26] and expression of cytokines. Molecules like glucans are relatively resistant to the stomach acid and are trapped by macrophage receptors present on the intestinal wall as the dectin-1, the toll-like receptor 2 (a class of proteins that play a role in immune system) and lactosylceramides The $\beta$-glucans with its various structures have different affinities for these receptors to elicit different host responses [16]. In vivo studies showed that the analysis of cytokine expression after administration of $\beta$-glucan isolated from $L$. edodes (lentinan) revealed a significant increase in mRNA levels of Interleukin-1 $\alpha$, interleukin- $1 \beta$, tumor necrosis factor- $\alpha(\mathrm{TNF}-\alpha)$ and interferon- $\delta(\mathrm{IFN}-\delta)$.

This result indicates a good response in the homeostasis of various diseases (Figure 2) [27] [28].

To date its anti-tumor activity remains unclear as some authors relate this activity with increasing cell-mediated immune response [29] [30]. However, other authors have shown anti-tumor activity with a direct effect on the cell, without involving the immune system [31].

In a study to investigate the effect of lentinan on $\mathrm{T}$ cells, when administered intraperitoneally, resulted in complete tumor regression in mice inoculated with cells FBL-3 (erythroleukemia).

The immunological effect was further confirmed when the inhibition of tumor growth stopped by administration of monoclonal antibodies against CD4 and CD8 prior to administration of $\beta$-glucan [32] [33]. These effects could be helpful in a number of disease states, but the significance of some of these findings in terms of potential medicinal value still has to be established [34]-[36]. A recent clinical study showed that chemo-immunotherapy using lentinan prolongs the survival of patients with advanced gastric cancer, as compared to chemotherapy alone [37]. In a study conducted by Lee et al. [38] crude water-soluble polysaccharides obtained from $L$. edodes by hot water extraction and ethanol precipitation activated macrophages and showed the increased of nitric oxide (NO), cytokines and phagocytosis expression.

An innovative strategy was suggested by Chen [39], using $\beta$-glucans to deliver nanoparticles containing chemotherapeutic agents to the site of the colon cancer and, thus, improving the therapeutic efficacy.

The anti-tumour effects of shiitake feed in murine models has interact with the effects of lentinan, which has been reported to prevent both chemical and viral carcinogenesis [40] [41].

Hazama et al. [42] demonstrated the efficacy of oral administration of lentinan in the treatment of advanced colorectal cancer (Figure 3). Shimizu et al. [43] also revealed good results in advanced pancreatic cancer, both with increased parameters of survival. Multicenter studies also looked at the effectiveness of the administration of lentinan in patients with hepatocellular carcinoma, resulting in increased survival time of these patients [44] [45]. 


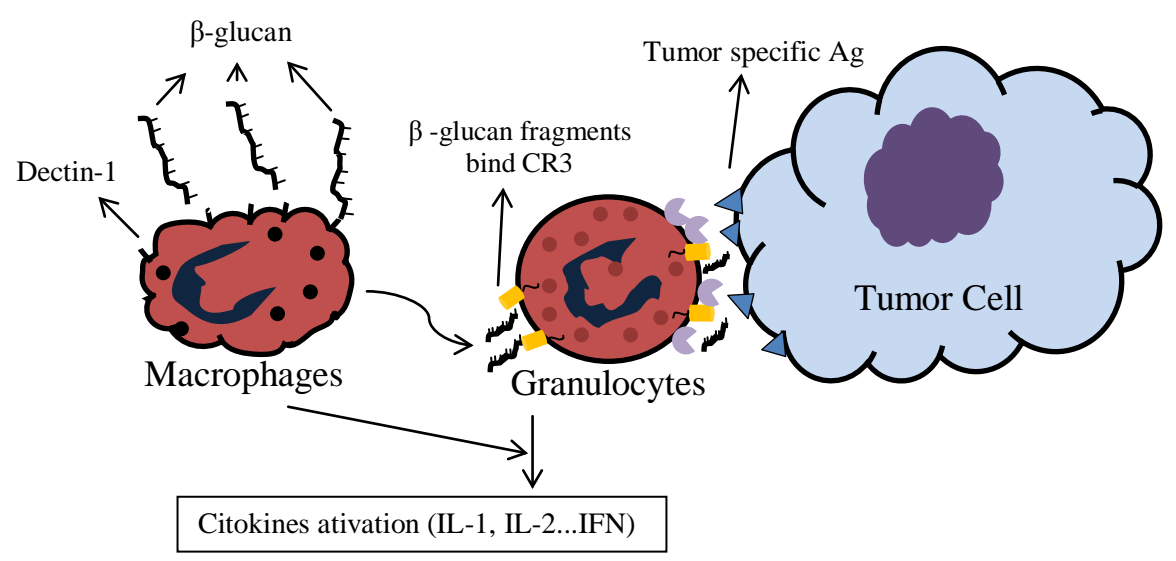

Figure 2. Immune system activation and cytokine production.

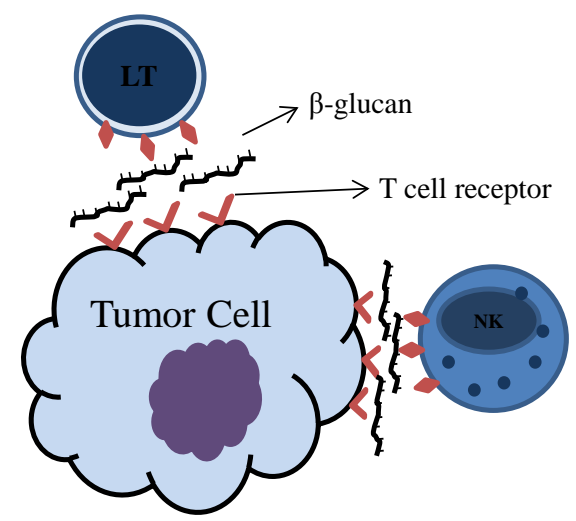

Figure 3. Neutralization of immunosuppressive factors.

Yamaguchi et al. [46] suggests the concomitant use of L. edodes mycelia (LEM) extracts to chemotherapy, resulting in a synergistic action to improve the quality of patients life. Another compound derived from the extract of $L$. edodes, the Active Hexose Correlated Compound (AHCC), also proved effective as adjunctive therapy in patients with cancer [47]-[49]. According to Ritz [49], oral supplementation with AHCC demonstrates a potential clinically relevant agent that enhances the immune system.

Studies have shown that some active substances present in $L$. edodes exert a protective effect against mutagenesis and carcinogenesis [50]. Aqueous extracts of L. edodes demonstrated direct inhibition of the proliferation of breast cancer cells in vitro and show to have immunostimulating properties in terms of mitogenic activity and co-mitogenic (Figure 4) [51]. In addition, antimutagenic and antigenotoxic effects evaluated by micronucleus and the comet test showed that extracts of shiitake have a antigenotoxic and antimutagenic activity in vivo [52] [53].

However, further studies to define the relationship between exposure to the mutagen, the required amount of Shiitake mushroom intake and the frequency of mutations, are still needed [52]. Basically, their antitumor abilities are influenced by the molecular mass, branching configuration, conformation, and chemical modification of the polysaccharides [36].

\section{Antioxidant Effects of $L_{\text {. }}$ edodes}

Our body has antioxidant defense systems that are often insufficient to completely prevent the damage caused by oxidative stress [54]. Thus, natural products such as mushrooms containing bioactive compounds can be used to help reduce such damage in the body [55]. As nutraceuticals, they activate endogenous protective system, generation important antioxidant role for the homeostasis of the organism [18] [35] [54]. Several studies have demonstrated the antioxidant properties of $L$. edodes for different; the extract on conditions. Study has performed 
tests with aqueous extract of the fruiting body [24], fractions of different molecular weight of polysaccharides [56], crude extract of polysaccharide (LEP) [57] [58] and exudates obtained from the mycelium (DE) [59]. All reports have shown antioxidant activity with high phenolic content (Table 2).

\section{Antiviral Activities of L. edodes}

Recent studies have determined the antiviral activity of extracts from LEP on the replication of poliovirus type 1 (PV-1) and bovine herpes virus type 1 (BoHV-1) and the results were anti-virus activity in promoting [60].

The isolated compound lentinan suppressed the activity of HIV-1 reverse transcriptase. In combination with antiretroviral 3'-azido-3'-deoxythymidine (AZT) lentinan suppressed the in vitro expression of surface antigens of HIV more efficiently compared to AZT monotherapy. It was also shown that it can increase the in vitro antiretroviral effect on HIV replication [61].

Tochikura et al. [62] tested many substances using non-sulfated polysaccharides (EP-LEM) and achieved inhibition for HIV-1, HIV-2 and HTLV-1. In another study, various fractions of LEM caused inhibition of infectivity and cytopathic effect of HIV [63] [64]. The mechanism of action is unclear, but it suggests that it may be related to activation of macrophages and stimulation of IL-1 [9]. A list of different extracts and its anti-viral activity is shown in Table 3.

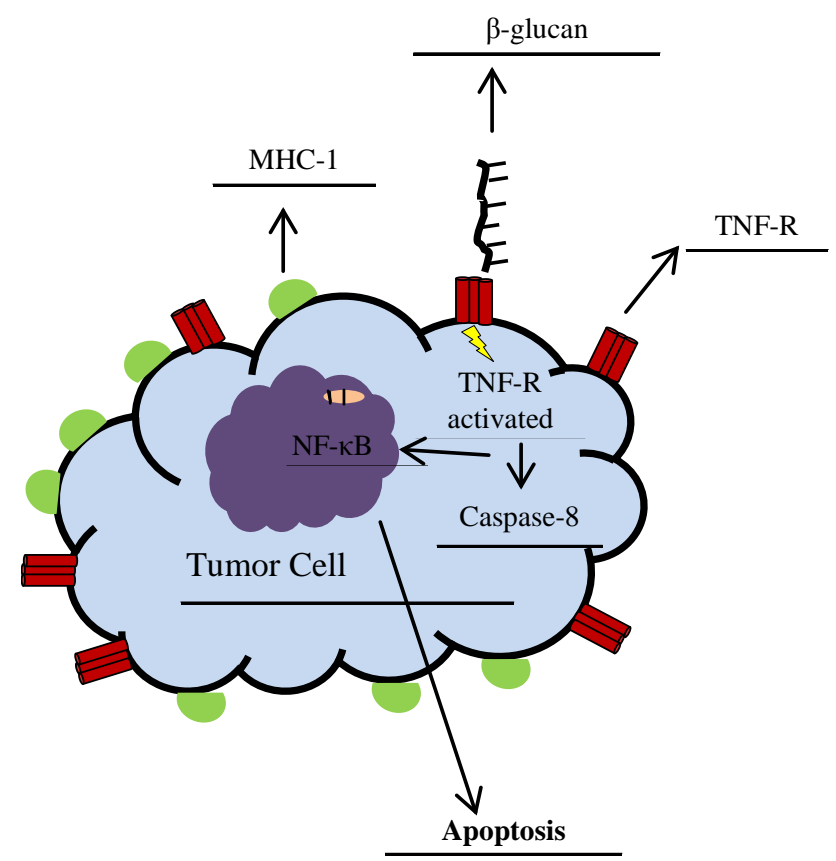

Figure 4. Direct action for induction of apoptosis and increased expression of MHC-1.

Table 2. Positive response against tumor cell line using different extracts of $L$. edodes.

\begin{tabular}{ccc}
\hline Extract & Cell line & Reference \\
\hline Low temperature aqueous total extract & Hep-2, HeLa in vitro & {$[24]$} \\
Isolated Lentinan & FBL-3 erythroleukemia cells & {$[81]$} \\
Methanol aqueous total extract & In vitro cell line MCF-7 & {$[51]$} \\
Mycelia-oral ingestion & Mouse (Colon-26) & {$[82]$} \\
Mycelia-oral ingestion & Mouse (B16 melanoma) & {$[83]$} \\
Isolated $\alpha$-(1,4) glucans & A549 in vitro & {$[28]$} \\
Ethyl acetate fraction & MDA-MB-453, MCF-7, MCF-10F, RPMI-8226, IM-9 in vitro & {$[84]$} \\
\hline
\end{tabular}


Table 3. L. edodes mycelia extracts and anti-viral activity.

\begin{tabular}{ccc}
\hline Extract & Microorganism & References \\
\hline Isolated lentinan derivate sulphated & West Nile virus & {$[10]$} \\
Hot water total extract & Poliovirus type 1 (PV-1) & {$[60]$} \\
Ethanolic total extract & Isolated polysaccharide \\
Isolated lentinan & Isolated laccase \\
Polysaccharide sulphated & Bovine Herpes virus type 1 (BoHV-1) \\
Polysaccharide nonsulfated & HIV-1 & {$[64][85]$} \\
Glycyrrhizin sulphated Lentinan sulphated & HIV-2 & HTLV-1 \\
\hline
\end{tabular}

\section{Antimicrobial Activities of L. edodes}

It has been reported that extracts of shiitake possess antibacterial activity enhancing host immunity against infections [34] [50] [64] [65]. Hatvani [63] used solvents like chloroform and ethyl acetate in dried mushroom and demonstrated bactericidal activity. Lenthionine, a cyclic organosulfur compound partially responsible for the taste of shiitake showed inhibitory effects against Staphylococcus aureus, Bacillus subtilis and Escherichia coli. Several studies have shown the ability of the extract of $L$. edodes to inhibit oral pathogens, mainly causing cavities and gingivitis [66]-[70].

According to Spratt et al. [71], the fraction of low molecular weight (LMM) isolated from the aqueous extract of $L$. edodes also has potential activity against oral pathogens in vitro. A list of different extracts and its antimicrobial activity is shown in Table 4.

\section{Other Biological Activities of L. edodes}

The hypoglycemic effect of an exo-polymer produced from a submerged culture of the $L$. edodes mycelium was investigated in rats with induced diabetes, and obtained a reduction in plasma glucose level compared to the control group. The reduction of cholesterol and triglyceride was also observed [72]. In a study by Akamatsu et al. [73], fractions obtained from aqueous extraction of L. edodes was examined for its hepatoprotective effect in injured rats. The reduced levels of aspartate aminotransferase and alanine aminotransferase in the blood were observed. These hepatoprotective effects are explained by the presence of polyphenols contained in fractions [72] [74] [75]. Polyphenols contained in both fractions are considered to be potential candidates for expressing the hepatoprotective effects [35] [76].

Cardiovascular disease is the leading cause of cholesterol levels in the blood throughout the world and is an important risk factor for the high mortality, therefore hypocholesteremic effects are of great importance. The ability of shiitake in lowering sanguine cholesterol was first reported in the 1960s [12]. To date, some studies demonstrate the ability of $L$. edodes in both decrease very low density lipoproteins (VLDL) as well as high density lipoproteins (HDL), preventing the increase of blood pressure [45] [77].

The consensus is that regular consumption of fruits and vegetables reduce the risk of cardiovascular disease (CVD). This is due to the antioxidant activity and immunomodulation exerted by these class of food [78]. Evidence also shows that mushrooms may protect against chronic disease like CVD. Oxidative stress and inflammation are closely linked to atherogenesis [68]. The mechanism of action is due to a significant reduction in binding of quiescent monocytes and also stimulated by cytokines [78] [79].

The main active component isolated from $L$. edodes associated to this function is the eritadenine. It reduces the lipid components of serum lipoproteins both in animals and in humans [80]. According to Isoda et al. [44], the oral administration of this compound proved to be effective and demonstrate low toxicity, although only $10 \%$ is absorbed in the gastrointestinal. As intravenous administration, it proved completely ineffective, and quickly eliminated from circulation and excreted by the kidneys.

\section{Conclusion}

The $L$. edodes is a macrofungus, that presents a variety of nutrition compounds, with great potential for therapeutic application. The activity and use of this macrofungus are unquestionable in some of the most important 
Table 4. L. edodes extracts against antimicrobial activity.

\begin{tabular}{ccc}
\hline Extract & Microorganism & References \\
\hline Low molecular weight & Actinomyces naeslundii & {$[69][86]$} \\
Dry aqueous extract total & Bacillus cereus & {$[65]$} \\
Dry aqueous extract total & Bacillus subtilis & {$[65][87]$} \\
Dry aqueous extract total & Enterococcus faecalis & {$[87]$} \\
Isolated liquid medium & Listeria monocytogenes & {$[65]$} \\
Dry aqueous extract total & Staphylococcus aureus & {$[65]$} \\
Dry aqueous extract total & MRSA & {$[86][69]$} \\
Low molecular weight & Fusobacterium nucleatum & {$[87]$} \\
Isolated liquid medium & Klebsiella pneumoniae & {$[65]$} \\
Isolated liquid medium & Proteus mirabilis & {$[86]$} \\
\hline
\end{tabular}

areas of applied biotechnology. Medicinal value of mushroom intake has become a matter of great significance, particularly in preventing or treating serious chronic conditions such as cancer and cardiovascular disease. From a pharmacological point of view, safety is the primary issue and research in this direction is desired. To date, $L$. edodes has shown to present a great potential for the production of useful bioactive metabolites that serve as a rich resource for drugs. Further research however is needed to establish content and bioactivity of the many compounds found in edible mushrooms.

\section{Acknowledgements}

This work was supported by a grant from Coordenação de Aperfeiçoamento de Pessoal de Nível Superior (CAPES) and Fundação de Amparo à Pesquisa do Estado do Rio Grande do Sul (FAPERGS).

\section{References}

[1] Newman, D.J. and Cragg, G.M. (2007) Natural Products as Sources of New Drugs over the Last 25 Years. Journal of Natural Products, 70, 461-477. http://dx.doi.org/10.1021/np068054v

[2] Lull, C., Wichers, H.J. and Savelkoul, H.F. (2005) Antiinflammatory and Immunomodulating Properties of Fungal Metabolites. Mediators of Inflammation, 2005, 63-80. http://dx.doi.org/10.1155/MI.2005.63

[3] Zhang, L., Fan, C., Liu, S., Zang, Z., Jiao, L. and Zhang, L. (2011) Chemical Composition and Antitumor Activity of Polysaccharide from Inonotus obliquus. Journal of Medicinal Plants Research, 5, 1251-1260.

[4] Yu, S., Weaver, V., Martin, K. and Cantorna, M.T. (2009) The Effects of Whole Mushrooms during Inflammation. BMC Immunology, 10, 12. http://dx.doi.org/10.1186/1471-2172-10-12

[5] Ali, S.H. (2010) The World of $\beta$-Glucans-A Review of Biological Roles, Applications and Potential Areas of Research. University Hospital of North Norway, Tromsø.

[6] Qiu, S., Huang, S., Huang, J., Pan, J. and Zhang, W. (2010) Antitumor Activity of the Water-Soluble Polysaccharide from Hyriopsis cumingii in Vitro. Toxicology and Industrial Health, 26, 151-161. http://dx.doi.org/10.1177/0748233710362376

[7] Santos-Neves, J.C., Pereira, M.I., Carbonero, E.R., Gracher, A.H.P., Alquini, G., Gorin, P.A.J., Sassaki, G.L. and Iacomini, M. (2008) A Novel Branched $\beta$-Glucan Isolated from the Basidiocarps of the Edible Mushroom Pleurotus florida. Carbohydrate Polymers, 73, 309-314. http://dx.doi.org/10.1016/j.carbpol.2007.11.030

[8] Unursaikhan, S., Xu, X., Zeng, F. and Zhang, L. (2006) Antitumor Activities of O-Sulfonated Derivatives of (1 $\rightarrow 3$ )- $\alpha$ D-Glucan from Different Lentinus edodes. Bioscience, Biotechnology, and Biochemistry, 70, 38-46. http://dx.doi.org/10.1271/bbb.70.38

[9] Wasser, S.P. (2002) Medicinal Mushrooms as a Source of Antitumor and Immunomodulating Polysaccharides. Applied Microbiology and Biotechnology, 60, 258-274. http://dx.doi.org/10.1007/s00253-002-1076-7

[10] Wang, X. and Zhang, L. (2009) Physicochemical Properties and Antitumor Activities for Sulfated Derivatives of Lentinan. Carbohydrate Research, 344, 2209-2216. http://dx.doi.org/10.1016/j.carres.2009.04.033 
[11] Petravić-tominac, V., Zechner-krpan, V., Grba, S., Srečec, S., Panjkota-krbavčić, I. and Vidović, L. (2010) Biological Effects of Yeast $\beta$-Glucans. Agriculturae Conspectus Scientificus, 75, 149-158.

[12] Bisen, P.S., Baghel, R.K., Sanodiya, B.S., Thakur, G.S. and Prasad, G.B. (2010) Lentinus edodes: A Macrofungus with Pharmacological Activities. Current Medicinal Chemistry, 17, 2419-2430. http://dx.doi.org/10.2174/092986710791698495

[13] Mizuno, T. (1995) Shiitake, Lentinus edodes: Functional Properties for Medicinal and Food Purposes. Food Reviews International, 11, 109-128. http://dx.doi.org/10.1080/87559129509541022

[14] Suzuki, F., Suzuki, C., Shimomura, E., Maeda, H., Fujii, T. and Ishida, N. (1979) Antiviral and Interferon-Inducing Activities of a New Peptidomannan, KS-2, Extracted from Culture Mycelia of Lentinus edodes. The Journal of Antibiotics (Tokyo), 32, 1336-1345. http://dx.doi.org/10.7164/antibiotics.32.1336

[15] Yamashita, A., Ohtsuka, H. and Maeda, H. (1983) Intestinal Absorption and Urinary Excretion of Antitumor Peptidomannan KS-2 after Oral Administration in Rats. Immunopharmacology, 5, $209-220$. http://dx.doi.org/10.1016/0162-3109(83)90028-0

[16] Rop, O., Mlcek, J. and Jurikova, T. (2009) Beta-Glucans in Higher Fungi and Their Health Effects. Nutrition Reviews, 67, 624-631. http://dx.doi.org/10.1111/j.1753-4887.2009.00230.x

[17] Heleno, S.A., Barros, L., Martins, A., Queiroz, M.J., Santos-Buelga, C. and Ferreira, I.C. (2012) Phenolic, Polysaccharidic, and Lipidic Fractions of Mushrooms from Northeastern Portugal: Chemical Compounds with Antioxidant Properties. Journal of Agricultural and Food Chemistry, 60, 4634-4640. http://dx.doi.org/10.1021/jf300739m

[18] Reis, F.S., Martins, A., Barros, L. and Ferreira, I.C. (2012) Antioxidant Properties and Phenolic Profile of the Most Widely Appreciated Cultivated Mushrooms: A Comparative Study between in Vivo and in Vitro Samples. Food and Chemical Toxicology, 50, 1201-1207. http://dx.doi.org/10.1016/j.fct.2012.02.013

[19] Chandra, L.C., Smith, B.J., Clarke, S.L., Marlow, D., D’Offay, J.M. and Kuvibidila, S.R. (2011) Differential Effects of Shiitake- and White Button Mushroom-Supplemented Diets on Hepatic Steatosis in C57BL/6 Mice. Food and Chemical Toxicology, 49, 3074-3080. http://dx.doi.org/10.1016/j.fct.2011.09.001

[20] Ikekawa, T., Uehara, N., Maeda, Y., Nakanishi, M. and Fukuoka, F. (1969) Antitumor Activity of Aqueous Extracts of Edible Mushrooms. Cancer Research, 29, 734-735.

[21] Ferreira, I.C., Vaz, J.A., Vasconcelos, M.H. and Martins, A. (2010) Compounds from Wild Mushrooms with Antitumor Potential. Anti-Cancer Agents in Medicinal Chemistry, 10, 424-436. http://dx.doi.org/10.2174/1871520611009050424

[22] Xu, X., Yasuda, M., Nakamura-Tsuruta, S., Mizuno, M. and Ashida, H. (2012) $\beta$-Glucan from Lentinus edodes Inhibits Nitric Oxide and Tumor Necrosis Factor- $\alpha$ Production and Phosphorylation of Mitogen-Activated Protein Kinases in Lipopolysaccharide-Stimulated Murine RAW 264.7 Macrophages. Journal of Biological Chemistry, 287, 871-878. http://dx.doi.org/10.1074/jbc.M111.297887

[23] Oh, J.Y., Baek, Y.M., Kim, S.W., Hwang, H.J., Hwang, H.S., Lee, S.H. and Yun, J.W. (2008) Apoptosis of Human Hepatocarcinoma (HepG2) and Neuroblastoma (SKN-SH) Cells Induced by Polysaccharides-Peptide Complexes Produced by Submerged Mycelial Culture of an Entomopathogenic Fungus Cordyceps sphecocephala. Journal of Microbiology and Biotechnology, 18, 512-519.

[24] Finimundy, T.C., Gambato, G., Fontana, R., Camassola, M., Salvador, M., Moura, S., Hess, J., Henriques, J.A., Dillon, A.J. and Roesch-Ely, M. (2013) Aqueous Extracts of Lentinula edodes and Pleurotus sajor-caju Exhibit High Antioxidant Capability and Promising in Vitro Antitumor Activity. Nutrition Research, 33, 76-84. http://dx.doi.org/10.1016/j.nutres.2012.11.005

[25] Yukawa, H., Ishikawa, S., Kawanishi, T., Tamesada, M. and Tomi, H. (2012) Direct Cytotoxicity of Lentinula edodes Mycelia Extract on Human Hepatocellular Carcinoma Cell Line. Biological and Pharmaceutical Bulletin, 35, 10141021. http://dx.doi.org/10.1248/bpb.b110657

[26] Takeshita, K., Hayashi, S., Tani, M., Kando, F., Saito, N. and Endo, M. (1996) Monocyte Function Associated with Intermittent Lentinan Therapy after Resection of Gastric Cancer. Surgical Oncology, 5, 23-28. http://dx.doi.org/10.1016/S0960-7404(96)80018-1

[27] Liu, F., Ooi, V.E. and Fung, M.C. (1999) Analysis of Immunomodulating Cytokine mRNAs in the Mouse Induced by Mushroom Polysaccharides. Life Sciences, 64, 1005-1011. http://dx.doi.org/10.1016/S0024-3205(99)00027-2

[28] Lo, T.C., Hsu, F.M., Chang, C.A. and Cheng, J.C. (2011) Branched $\alpha$-(1,4) Glucans from Lentinula edodes (L10) in Combination with Radiation Enhance Cytotoxic Effect on Human Lung Adenocarcinoma through the Toll-Like Receptor 4 Mediated Induction of THP-1 Differentiation/Activation. Journal of Agricultural and Food Chemistry, 59, 11997-12005. http://dx.doi.org/10.1021/jf202457r

[29] Ooi, V.E. and Liu, F. (2000) Immunomodulation and Anti-Cancer Activity of Polysaccharide-Protein Complexes. Current Medicinal Chemistry, 7, 715-729. http://dx.doi.org/10.2174/0929867003374705 
[30] Chanput, W., Reitsma, M., Kleinjans, L., Mes, J.J., Savelkoul, H.F. and Wichers, H.J. (2012) $\beta$-Glucans Are Involved in Immune-Modulation of THP-1 Macrophages. Molecular Nutrition \& Food Research, 56, 822-833. http://dx.doi.org/10.1002/mnfr.201100715

[31] Zhuang, C., Mizuno, T., Shimada, A., Ito, H., Suzuki, C., Mayuzumi, Y., Okamoto, H., Ma, Y. and Li, J. (1993) Antitumor Protein-Containing Polysaccharides from a Chinese Mushroom Fengweigu or Houbitake, Pleurotus sajor-caju (Fr.) Sings. Bioscience, Biotechnology, and Biochemistry, 57, 901-906. http://dx.doi.org/10.1271/bbb.57.901

[32] Suzuki, M., Iwashiro, M., Takatsuki, F., Kuribayashi, K. and Hamuro, J. (1994) Reconstitution of Anti-Tumor Effects of Lentinan in Nude Mice: Roles of Delayed-Type Hypersensitivity Reaction Triggered by CD4-Positive T Cell Clone in the Infiltration of Effector Cells into Tumor. Cancer Science, 85, 409-417. http://dx.doi.org/10.1111/j.1349-7006.1994.tb02374.x

[33] Liu, C., Gao, P., Qian, J. and Yan, W. (2000) Immunological Study on the Antitumor Effects of Fungus Polysaccharides Compounds. Wei Sheng Yan Jiu, 29, 178-180.

[34] Rao, J.R., Smyth, T.J., Millar, B.C. and Moore, J.E. (2009) Antimicrobial Properties of Shiitake Mushrooms (Lentinula edodes). International Journal of Antimicrobial Agents, 33, 591-592. http://dx.doi.org/10.1016/j.ijantimicag.2008.10.018

[35] Carneiro, A.A., Ferreira, I.C., Duenas, M., Barros, L., Da Silva, R., Gomes, E. and Santos-Buelga, C. (2013) Chemical Composition and Antioxidant Activity of Dried Powder Formulations of Agaricus blazei and Lentinus edodes. Food Chemistry, 138, 2168-2173. http://dx.doi.org/10.1016/j.foodchem.2012.12.036

[36] Ren, L., Perera, C. and Hemar, Y. (2012) Antitumor Activity of Mushroom Polysaccharides: A Review. Food \& Function, 3, 1118-1130. http://dx.doi.org/10.1039/c2fo10279j

[37] Ina, K. and Ando, T. (2012) The Use of Lentinan for Treating Gastric Cancer. Anti-Cancer Agents in Medicinal Chemistry, 13, 681-688. http://dx.doi.org/10.2174/1871520611313050002

[38] Lee, H.H., Lee, J.S., Cho, J.Y., Kim, Y.E. and Hong, E.K. (2009) Study on Immunostimulating Activity of Macrophage Treated with Purified Polysaccharides from Liquid Culture and Fruiting Body of Lentinus edodes. Journal of Microbiology and Biotechnology, 19, 566-572.

[39] Chen, J. (2012) Recent Advance in the Studies of $\beta$-Glucans for Cancer Therapy. Anti-Cancer Agents in Medicinal Chemistry, 13, 679-680. http://dx.doi.org/10.2174/1871520611313050001

[40] Chihara, G., Maeda, Y., Hamuro, J., Sasaki, T. and Fukuoka, F. (1969) Inhibition of Mouse Sarcoma 180 by Polysaccharides from Lentinus edodes (Berk.) Sing. Nature, 222, 687-688. http://dx.doi.org/10.1038/222687a0

[41] Kurashige, S., Akuzawa, Y. and Endo, F. (1997) Effects of Lentinus edodes, Grifola frondosa and Pleurotus ostreatus Administration on Cancer Outbreak, and Activities of Macrophages and Lymphocytes in Mice Treated with a Carcinogen, N-Butyl-N-Butanolnitrosoamine. Immunopharmacology and Immunotoxicology, 19, 175-183. http://dx.doi.org/10.3109/08923979709007657

[42] Hazama, S., Watanabe, S., Ohashi, M., Yagi, M., Suzuki, M., Matsuda, K., Yamamoto, T., Suga, Y., Suga, T., Nakazawa, S. and Oka, M. (2009) Efficacy of Orally Administered Superfine Dispersed Lentinan ( $\beta$-1,3-glucan) for the Treatment of Advanced Colorectal Cancer. Anticancer Research, 29, 2611-2617.

[43] Shimizu, K., Watanabe, S., Matsuda, K., Suga, T., Nakazawa, S. and Shiratori, K. (2009) Efficacy of Oral Administered Superfine Dispersed Lentinan for Advanced Pancreatic Cancer. Hepatogastroenterology, 56, 240-244.

[44] Isoda, N., Eguchi, Y., Nukaya, H., Hosho, K., Suga, Y., Suga, T., Nakazawa, S. and Sugano, K. (2009) Clinical Efficacy of Superfine Dispersed Lentinan ( $\beta$-1,3-glucan) in Patients with Hepatocellular Carcinoma. Hepatogastroenterology, 56, 437-441.

[45] Oba, K., Kobayashi, M., Matsui, T., Kodera, Y. and Sakamoto, J. (2009) Individual Patient Based Meta-Analysis of Lentinan for Unresectable/Recurrent Gastric Cancer. Anticancer Research, 29, 2739-2745.

[46] Yamaguchi, Y., Miyahara, E. and Hihara, J. (2011) Efficacy and Safety of Orally Administered Lentinula edodes Mycelia Extract for Patients Undergoing Cancer Chemotherapy: A Pilot Study. American Journal of Chinese Medicine, 39, 451-459. http://dx.doi.org/10.1142/S0192415X11008956

[47] Shah, S.K., Walker, P.A., Moore-Olufemi, S.D., Sundaresan, A., Kulkarni, A.D. and Andrassy, R.J. (2011) An EvidenceBased Review of a Lentinula edodes Mushroom Extract as Complementary Therapy in the Surgical Oncology Patient. JPEN Journal of Parenteral and Enteral Nutrition, 35, 449-458. http://dx.doi.org/10.1177/0148607110380684

[48] Aleem, E. (2012) $\beta$-Glucans and Their Applications in Cancer Therapy: Focus on Human Studies. Anti-Cancer Agents in Medicinal Chemistry, 13, 709-719.

[49] Ritz, B.W. (2008) Supplementation with Active Hexose Correlated Compound Increases Survival Following Infectious Challenge in Mice. Nutrition Reviews, 66, 526-531. http://dx.doi.org/10.1111/j.1753-4887.2008.00085.x

[50] Mantovani, M.S., Bellini, M.F., Angeli, J.P., Oliveira, R.J., Silva, A.F. and Ribeiro, L.R. (2008) $\beta$-Glucans in Promot- 
ing Health: Prevention against Mutation and Cancer. Mutation Research, 658, 154-161. http://dx.doi.org/10.1016/j.mrrev.2007.07.002

[51] Israilides, C., Kletsas, D., Arapoglou, D., Philippoussis, A., Pratsinis, H., Ebringerova, A., Hribalova, V. and Harding, S.E. (2008) In Vitro Cytostatic and Immunomodulatory Properties of the Medicinal Mushroom Lentinula edodes. Phytomedicine, 15, 512-519. http://dx.doi.org/10.1016/j.phymed.2007.11.029

[52] Miyaji, C.K., Poersch, A., Ribeiro, L.R., Eira, A.F. and Colus, I.M. (2006) Shiitake (Lentinula edodes (Berkeley) Pegler) Extracts as a Modulator of Micronuclei Induced in HEp-2 Cells. Toxicology in Vitro, 20, 1555-1559. http://dx.doi.org/10.1016/j.tiv.2006.07.004

[53] de Lima, P.L., Delmanto, R.D., Sugui, M.M., da Eira, A.F., Salvadori, D.M., Speit, G. and Ribeiro, L.R. (2001) Letinula edodes (Berk.) Pegler (Shiitake) Modulates Genotoxic and Mutagenic Effects Induced by Alkylating Agents in Vivo. Mutation Research, 496, 23-32. http://dx.doi.org/10.1016/S1383-5718(01)00215-7

[54] Da Silva, A.C. and Jorge, N. (2011) Antioxidant Properties of Lentinus edodes and Agaricus Blazei Extracts. Journal of Food Quality, 34, 386-394. http://dx.doi.org/10.1111/j.1745-4557.2011.00416.x

[55] Mohsin, M., Negi, P. and Ahmed, Z. (2011) Determination of the Antioxidant Activity and Polyphenol Contents of Wild Lingzhi or Reishi Medicinal Mushroom, Ganoderma lucidum (W.Curt. Fr.) P. Karst. (Higher Basidiomycetes) from Central Himalayan Hills of India. International Journal of Medicinal Mushrooms, 13, 535-544. http://dx.doi.org/10.1615/IntJMedMushr.v13.i6.50

[56] You, R., Wang, K., Liu, J., Liu, M., Luo, L. and Zhang, Y. (2011) A Comparison Study between Different Molecular Weight Polysaccharides Derived from Lentinus edodes and Their Antioxidant Activities in Vivo. Pharmaceutical Biology, 49, 1298-1305. http://dx.doi.org/10.3109/13880209.2011.621960

[57] Attitalla, I.H. (2011) Lentinus sp. RJ-2 Mushroom Is Important Source of Natural Antioxidative Polysaccharides. Pakistan Journal of Biological Sciences, 14, 1070-1071. http://dx.doi.org/10.3923/pjbs.2011.1070.1071

[58] Chen, H., Ju, Y., Li, J. and Yu, M. (2012) Antioxidant Activities of Polysaccharides from Lentinus edodes and Their Significance for Disease Prevention. International Journal of Biological Macromolecules, 50, 214-218. http://dx.doi.org/10.1016/j.ijbiomac.2011.10.027

[59] Huang, W., Kim, J.S. and Chung, H.Y. (2011) Antioxidant Activity and Total Phenolic Content in Shiitake Mycelial Exudates. Natural Product Communications, 6, 845-850.

[60] Rincao, V.P., Yamamoto, K.A., Ricardo, N.M., Soares, S.A., Meirelles, L.D., Nozawa, C. and Linhares, R.E. (2012) Polysaccharide and Extracts from Lentinula edodes: Structural Features and Antiviral Activity. Virology Journal, 9, 37. http://dx.doi.org/10.1186/1743-422X-9-37

[61] Jong, S.C. and Birmingham, J.M. (1993) Medicinal and Therapeutic Value of the Shiitake Mushroom. Advances in Applied Microbiology, 39, 153-184. http://dx.doi.org/10.1016/S0065-2164(08)70595-1

[62] Tochikura, T.S., Nakashima, H. and Yamamoto, N. (1989) Antiviral Agents with Activity against Human Retroviruses. Journal of Acquired Immune Deficiency Syndromes, 2, 441-447.

[63] Hatvani, N. (2001) Antibacterial Effect of the Culture Fluid of Lentinus edodes Mycelium Grown in Submerged Liquid Culture. International Journal of Antimicrobial Agents, 17, 71-74. http://dx.doi.org/10.1016/S0924-8579(00)00311-3

[64] Ngai, P.H. and Ng, T.B. (2003) Lentin, a Novel and Potent Antifungal Protein from Shitake Mushroom with Inhibitory Effects on Activity of Human Immunodeficiency Virus-1 Reverse Transcriptase and Proliferation of Leukemia Cells. Life Sciences, 73, 3363-3374. http://dx.doi.org/10.1016/j.lfs.2003.06.023

[65] Hearst, R., Nelson, D., McCollum, G., Millar, B.C., Maeda, Y., Goldsmith, C.E., Rooney, P.J., Loughrey, A., Rao, J.R. and Moore, J.E. (2009) An Examination of Antibacterial and Antifungal Properties of Constituents of Shiitake (Lentinula edodes) and Oyster (Pleurotus ostreatus) Mushrooms. Complementary Therapies in Clinical Practice, 15, 5-7. http://dx.doi.org/10.1016/j.ctcp.2008.10.002

[66] Lingstrom, P., Zaura, E., Hassan, H., Buijs, M.J., Hedelin, P., Pratten, J., Spratt, D., Daglia, M., Karbowiak, A., Signoretto, C., et al. (2012) The Anticaries Effect of a Food Extract (Shiitake) in a Short-Term Clinical Study. Journal of Biomedicine and Biotechnology, 2012, Article ID: 217164. http://dx.doi.org/10.1155/2012/217164

[67] Shouji, N., Takada, K., Fukushima, K. and Hirasawa, M. (2000) Anticaries Effect of a Component from Shiitake (an Edible Mushroom). Caries Research, 34, 94-98. http://dx.doi.org/10.1159/000016559

[68] Lindequist, U., Niedermeyer, T.H. and Julich, W.D. (2005) The Pharmacological Potential of Mushrooms. EvidenceBased Complementary and Alternative Medicine, 2, 285-299. http://dx.doi.org/10.1093/ecam/neh107

[69] Ciric, L., Tymon, A., Zaura, E., Lingstrom, P., Stauder, M., Papetti, A., Signoretto, C., Pratten, J., Wilson, M. and Spratt, D. (2011) In Vitro Assessment of Shiitake Mushroom (Lentinula edodes) Extract for Its Antigingivitis Activity. Journal of Biomedicine and Biotechnology, 2011, Article ID: 507908. http://dx.doi.org/10.1155/2011/507908

[70] Zaura, E., Buijs, M.J., Hoogenkamp, M.A., Ciric, L., Papetti, A., Signoretto, C., Stauder, M., Lingstrom, P., Pratten, J., Spratt, D.A. and Wilson, M. (2011) The Effects of Fractions from Shiitake Mushroom on Composition and Carioge- 
nicity of Dental Plaque Microcosms in an in Vitro Caries Model. Journal of Biomedicine and Biotechnology, 2011, Article ID: 135034. http://dx.doi.org/10.1155/2011/135034

[71] Spratt, D.A., Daglia, M., Papetti, A., Stauder, M., O’Donnell, D., Ciric, L., Tymon, A., Repetto, B., Signoretto, C., Houri-Haddad, Y., et al. (2012) Evaluation of Plant and Fungal Extracts for Their Potential Antigingivitis and Anticaries Activity. Journal of Biomedicine and Biotechnology, 2012, Article ID: 510198. http://dx.doi.org/10.1155/2012/510198

[72] Yamac, M., Kanbak, G., Zeytinoglu, M., Bayramoglu, G., Senturk, H. and Uyanoglu, M. (2008) Hypoglycemic Effect of Lentinus Strigosus (Schwein.) Fr. Crude Exopolysaccharide in Streptozotocin-Induced Diabetic Rats. Journal of Medicinal Food, 11, 513-517. http://dx.doi.org/10.1089/jmf.2007.0551

[73] Akamatsu, S., Watanabe, A., Tamesada, M., Nakamura, R., Hayashi, S., Kodama, D., Kawase, M. and Yagi, K. (2004) Hepatoprotective Effect of Extracts from Lentinus edodes Mycelia on Dimethylnitrosamine-Induced Liver Injury. Biological and Pharmaceutical Bulletin, 27, 1957-1960. http://dx.doi.org/10.1248/bpb.27.1957

[74] Yang, B.K., Kim, D.H., Jeong, S.C., Das, S., Choi, Y.S., Shin, J.S., Lee, S.C. and Song, C.H. (2002) Hypoglycemic Effect of a Lentinus edodes Exo-Polymer Produced from a Submerged Mycelial Culture. Bioscience, Biotechnology, and Biochemistry, 66, 937-942. http://dx.doi.org/10.1271/bbb.66.937

[75] Yagi, K. (2012) Liver Protective Effect of Lentinula Edodes Mycelia (LEM). Gan to Kagaku Ryoho. Cancer \& Chemotherapy, 39, 1099-1102.

[76] Yoshioka, Y., Kojima, H., Tamura, A., Tsuji, K., Tamesada, M., Yagi, K. and Murakami, N. (2012) Low-MolecularWeight Lignin-Rich Fraction in the Extract of Cultured Lentinula edodes Mycelia Attenuates Carbon TetrachlorideInduced Toxicity in Primary Cultures of Rat Hepatocytes. Journal of Natural Medicines, 66, 185-191. http://dx.doi.org/10.1007/s11418-011-0580-4

[77] Shimada, Y., Morita, T. and Sugiyama, K. (2002) Effects of Lentinus edodes on Fatty Acid and Molecular Species Profiles of Phosphatidylcholine in Rats Fed Different Levels of Corn Oil. Bioscience, Biotechnology, and Biochemistry, 66, 1759-1763. http://dx.doi.org/10.1271/bbb.66.1759

[78] Martin, K.R. (2010) Both Common and Specialty Mushrooms Inhibit Adhesion Molecule Expression and in Vitro Binding of Monocytes to Human Aortic Endothelial Cells in a Pro-Inflammatory Environment. Nutrition Journal, 9, 29. http://dx.doi.org/10.1186/1475-2891-9-29

[79] Martin, K.R. (2010) The Bioactive Agent Ergothioneine, a Key Component of Dietary Mushrooms, Inhibits Monocyte Binding to Endothelial Cells Characteristic of Early Cardiovascular Disease. Journal of Medicinal Food, 13, 13401346. http://dx.doi.org/10.1089/jmf.2009.0194

[80] Enman, J., Hodge, D., Berglund, K.A. and Rova, U. (2008) Production of the Bioactive Compound Eritadenine by Submerged Cultivation of Shiitake (Lentinus edodes) Mycelia. Journal of Agricultural and Food Chemistry, 56, 26092612. http://dx.doi.org/10.1021/jf800091a

[81] Liu, W., Wang, H., Pang, X., Yao, W. and Gao, X.D. (2000) Characterization and Antioxidant Activity of Two LowMolecular-Weight Polysaccharides Purified from the Fruiting Bodies of Ganoderma lucidum. International Journal of Biological Macromolecules, 46, 451-457. http://dx.doi.org/10.1016/j.ijbiomac.2010.02.006

[82] Tanaka, K., Ishikawa, S., Matsui, Y., Tamesada, M., Harashima, N. and Harada, M. (2011) Oral Ingestion of Lentinula edodes Mycelia Extract Inhibits B16 Melanoma Growth via Mitigation of Regulatory T Cell-Mediated Immunosuppression. Cancer Science, 102, 516-521. http://dx.doi.org/10.1111/j.1349-7006.2010.01841.x

[83] Tanaka, K., Matsui, Y., Ishikawa, S., Kawanishi, T. and Harada, M. (2012) Oral Ingestion of Lentinula edodes Mycelia Extract Can Restore the Antitumor T Cell Response of Mice Inoculated with Colon-26 Cells into the Subserosal Space of the Cecum. Oncology Reports, 27, 325-332.

[84] Fang, N., Li, Q., Yu, S., Zhang, J., He, L., Ronis, M.J. and Badger, T.M. (2006) Inhibition of Growth and Induction of Apoptosis in Human Cancer Cell Lines by an Ethyl Acetate Fraction from Shiitake Mushrooms. Journal of Alternative and Complementary Medicine, 12, 125-132. http://dx.doi.org/10.1089/acm.2006.12.125

[85] Sun, J., Chen, Q.J., Cao, Q.Q., Wu, Y.Y., Xu, L.J., Zhu, M.J., Ng, T.B., Wang, H.X. and Zhang, G.Q. (2012) A Laccase with Antiproliferative and HIV-I Reverse Transcriptase Inhibitory Activities from the Mycorrhizal Fungus Agaricus placomyces. Journal of Biomedicine and Biotechnology, 2012, Article ID: 736472. http://dx.doi.org/10.1155/2012/736472

[86] Hirasawa, M., Shouji, N., Neta, T., Fukushima, K. and Takada, K. (1999) Three Kinds of Antibacterial Substances from Lentinus edodes (Berk.) Sing. (Shiitake, an Edible Mushroom). International Journal of Antimicrobial Agents, 11, 151-157. http://dx.doi.org/10.1016/S0924-8579(98)00084-3

[87] Ishikawa, N.K., Kasuya, M.C.M. and Vanetti, M.C.D. (2001) Antibacterial Activity of Lentinula edodes Grown in Liquid Medium. Brazilian Journal of Microbiology, 32, 206-210.

http://dx.doi.org/10.1590/S1517-83822001000300008 
Scientific Research Publishing (SCIRP) is one of the largest Open Access journal publishers. It is currently publishing more than 200 open access, online, peer-reviewed journals covering a wide range of academic disciplines. SCIRP serves the worldwide academic communities and contributes to the progress and application of science with its publication.

Other selected journals from SCIRP are listed as below. Submit your manuscript to us via either submit@scirp.org or Online Submission Portal.
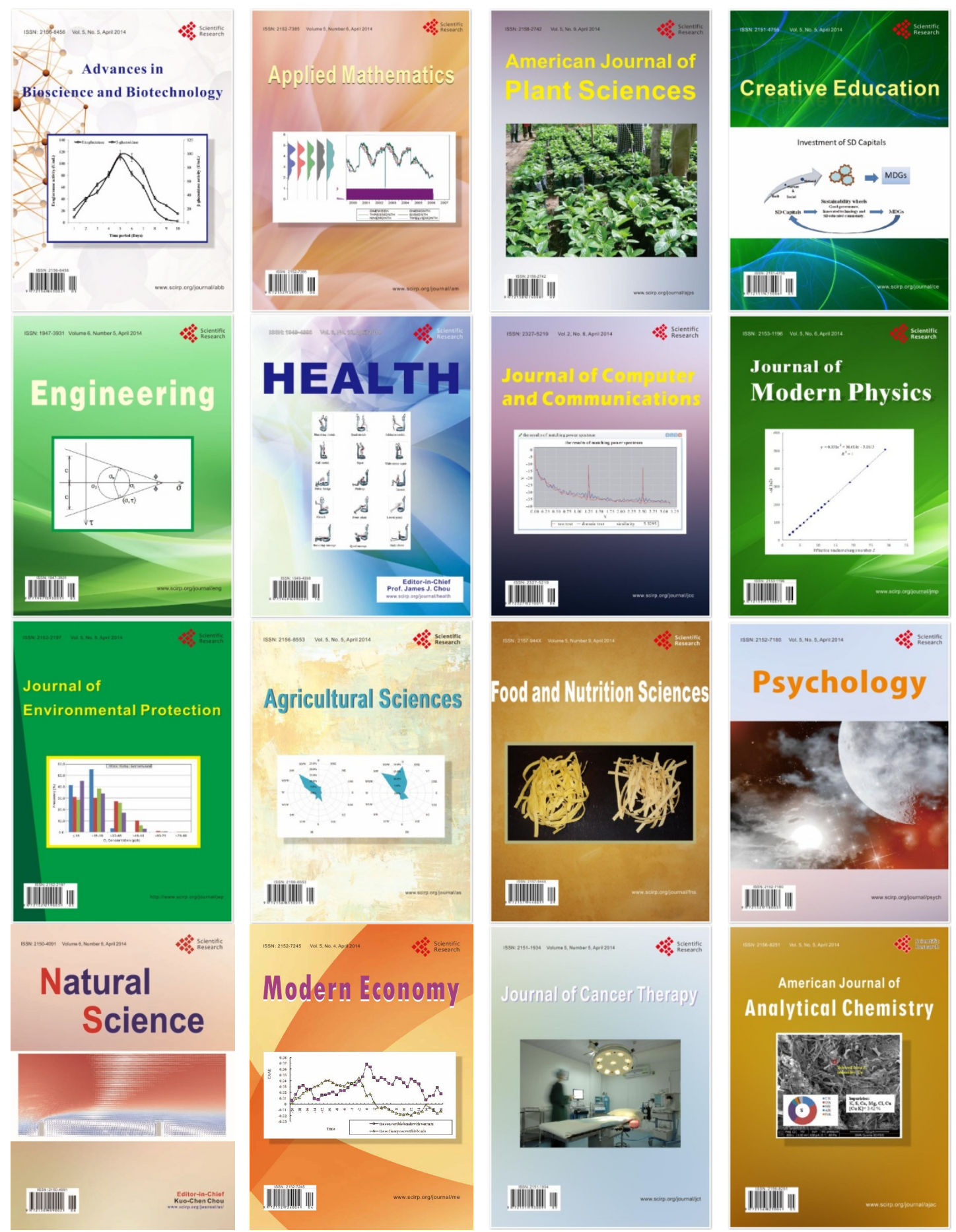